\title{
Exploring the Misrepresentation of Nigerian Women in Technical and Vocational Education in Polytechnic Institution
}

\author{
Robert Akor (Corresponding author) \\ Faculty of Educational Studies, Universiti Putra Malaysia, 43400 UPM, Serdang, Selangor, Malaysia \\ E-mail: obertakor43@yahoo.com
}

Ab Rahim Bin Bakar

Faculty of Educational Studies, Universiti Putra Malaysia, 43400 UPM, Serdang, Selangor, Malaysia

Azim B.Hj Hamzah

Faculty of Educational Studies, Universiti Putra Malaysia, 43400 UPM, Serdang, Selangor, Malaysia

Abdullah Bin Mat Rashid

Faculty of Educational Studies, Universiti Putra Malaysia, 43400 UPM, Serdang, Selangor, Malaysia

Received: 12-07- 2014

doi:10.7575/aiac.ijels.v.2n.4p.12
Accepted: 10-09-2014

Published: 30-10-2014

\begin{abstract}
Nigerian government is making frantic efforts to drive her economy by laying emphasis on technical and vocational education to enable her compete favorably in the global market. Emphasis of government is in Polytechnic education where skills for self-reliant and economic growth are a priority. However, women are not embracing this opportunity by participating in the program that will equip them with skills and contribute to national development. In all 14 female participants were purposefully selected from Polytechnic. Phenomenological methodology was adopted and data collected were transcribed and analyzed. Results from the study include math/science phobia, perceived social support, and contextual roles among reasons for misrepresentation of women in technical and vocational education. Unless women have increased access to technical and vocational education in order to build diverse technical skills their vulnerability to unemployment and poverty will be on the rise. The findings of this study will guide stakeholders to develop a framework for improving the enrollment of women in this field.
\end{abstract}

Keywords: women, technical and vocational education, self-reliant and unemployment

\section{Introduction}

It cannot be overemphasized that technical and vocational education (TVE) is a precursor for social, economic and industrial development of any nation. No society or nation today can go to war without well equipped army. The leading factors of production in the emerging global economy today are said to be technology, creativity and innovation. The vision 20:2020 that is being vicariously pursued by Nigerian government will remain a paper tiger if women that make up half the population is without technical and vocational education knowledge or skills.

Production of human resources both in developing and developed economy invariably entails equipping the youth (both male and female) with employability skills in technical and vocational education that will enable them live a functional and productive life. The scenario in Nigeria has been more males seeking and acquiring technical and vocational education than females at the Polytechnic institution. This no doubt spells doom for the technological and emancipation of the country especially as over half the entire population is females. Egun and Tibi (2010) observed that, Nigeria educational system especially technical and vocational education which has high potential to create jobs for the unemployed and solve most of the human problems is yet too embraced by majority of Nigerian women. Women are very important in nation building. National development is achieved only when individual (women and men) in any nation produces to their limit of their capabilities (Ogbuanya, 2008). Therefore, there can be no meaningful development in Nigeria if women are deprived of the opportunity to acquire technical and vocational education knowledge or skills.

It is as a result of the desire for technological development and economic self-reliant for the youth that the Federal Government of Nigeria in her revised version of National Policy on Education (FME,2004) gave prominence to technical and vocational education. To achieve technological development, the (FME,2004) stated that greater proportion of the expenditure on education shall be devoted to science and technical and vocational education courses at the Polytechnic institution, the weighting is the ration of 70:30. The FME (2004) version of (NPE) embodied some 
policy innovation and change including repositioning science, technical and vocational education for optimum performance. Another relevant part of the NPE is the emphasis on education as instrument per excellence for national development and that every child have the right to equal education opportunities irrespective of any real or imagined disabilities. From the provision of the NPE, it appears that Nigeria is concerned, not only with accessibility but also the quality of that accessibility in terms of national development. The NPE emphasized quality accessibility which implies that every Nigerian citizen, all girls and boys, women and men in school should be able to study those courses that are of national relevance without any hindrance. It also stressed the need for all Nigerians to be scientifically and technological literate in order to be able to exploit personal, national and natural resources to contribute to national development.

However, in spite of the policy of the government to promote technological education at all levels, Nigerian women remain misrepresented in technical and vocational education most particularly at the Polytechnic institution. The high demographic size, the important role women play in the economic development in Nigeria and the low participation in this field make it imperative to promote and encourage women's access and participation in this program. Thus, there is a need to explore why Nigerian women are misrepresented in this field so as to bring in more women into this domain.

\section{Research Purpose}

The provision of educational opportunities for women has been an important part of national endeavor in Nigeria since independence. Though these endeavors did yield significant results, gender disparity persists with uncompromising tenacity, more in technical and vocational education fields. Much of the existing data on women in technical and vocational education or nontraditional programs in Nigeria have been informed by research from the science field. A review of related studies shows lack of qualitative research on the misrepresentation of women in technical and vocational education program. According to Raghuram (2008) researchers have not given attention to the study of women in male-dominated occupation. Most studies focus on women in context-specific male-dominated professions like civil engineering, quantity surveying etc. from a predominantly quantitative perspective. Franks et al., (2006) conducted a qualitative inquiry into the life-role construction of career-oriented women and emphasized specifically the need for more in-depth qualitative work on why women are misrepresented in male-dominated occupation. A qualitative approach to the misrepresentation of these women in male-dominated technical and vocational education may contribute to the understanding of the factors that inhibit women's access to and participation in this field. Understanding the challenges women in this field encounter will enable the researcher to make suggestions that will improve the access to and participation of women in this field.

\section{Literature Review}

In spite of the modest improvement in the girls and women's education, gender disparity in technical and vocational education still exists. Cultural norms and value system have caused the misrepresentation of women in technical and vocational education in Polytechnic institution in Nigeria. Okpoko (2005) was of the opinion that many of the cultural and traditional practices advocated for females by the societies and families stem from the belief that these females are inferior, and must be controlled as well as prepared for domestic work. The traditional community believed that the place of girl-child and consequently women is in the kitchen or home and she is socialized into accepting her traditional role of bearing and rearing children and maintaining also the welfare of the family. The girl-child education is not expected to go beyond preparing her for assigned females roles, for example nursing teaching cooking and others while the male's are prepared for science, engineering, hunting etc. (Ajewole, 2000).

The masculine image associated with technical and vocational education and science related fields has been attributed to be among the reasons for non-participation of women in these fields in addition to lack of confidence in their scientific capabilities (Lohan \& Faulkner, 2004). In terms of professional teaching women prepare most in the field of secretarial, catering, hotelier and nursing (Egun \& Tibi, 2010). Most of these programs do not cater for modern technological demand and thus fail to generate employability for women. This, therefore, results in very few opportunities for women's socio-economic independence, thus further accentuating inequality in the society. The National Policy on Education (FME,2004) do not discriminate between sexes, rather they emphasis freedom, equality and justice.

Women's lack of equitable access to technical and vocational education program for skill development and nation building remain area of concern. Attitudinal and structural barriers prevent many women from fully participation as equal partners with men at home and in the community. They are often left out of the decision-making process and their contributions and ideas are regarded with lesser importance. This is particularly so, given the likelihood of the "double roles the customs and cultural particularities that tend to limit their participation. However, the gender disparity in access to primary, secondary and particularly higher education date back to the pre-colonial era and is rooted not only in African traditional culture, but also in Christianity and Islam in Nigeria (Akpoto, 2009). This can be seen to play a significant role in hindering girls and women's enrolment in technical and vocational education.

There exist perceived differences in the males and females' role and capabilities, inculcated through socialization in the males and females, reinforced through schooling vocational career guidance services, experience in the work place peer pressure and absence of female role models. Parents play a significant role in shaping the direction or path that their children will follow in their later life. Family processes of interaction and communication, as well as beliefs and attitudes influence what the child learns about work and work experience (FAWE, 2005). Simmons (2008) and Omadjohwoefe (2011) posit that both young boys and girls look on their parents when they make career choices. Girls indicated that their interest or lack of interest in technical and vocational education courses was based on their parents' 
opinion about the field of study (Ndahi, 2002). Parents' belief that the right place for their daughters is at home to work in the informal sector (commercial or field work) (Alabi \& Alabi, 2014). In similar vein Okpoko (2005) observed that in rural areas many Nigerian parents prefer to enroll the boy-child in school than the girl-child, especially in large families where funds are limited. This is because the parents believe that education is more important for the boy-child than for the girl-child.

In Nigerian society, women are restricted from participating in activates meant for men, especially those involving physical prowess because women are seen as the weaker sex. The discrimination exercise which Azikiwe (as cited in Alamina, 2001) sees as having become an integral part of the socialization process starts from birth, when children are socialized very early into sex type activities. Thus, while males are expected to go into such jobs that involve physical strains, logical thinking leadership and competition, women are expected to go into such jobs which are of lower status and less strenuous such as teaching, nursing, secretarial jobs etc. (Aguele \& Agwagah, 2007).

Social influence is also a strong factor as some parents are known to restrain girls from demonstrating their natural skill and developing their talents, rather than training girls along a stereotyped line of behavior. The other issue includes sexism in the curriculum which systematically causes girls to go into separate areas of the curriculum for boys. Girls may decide to take traditionally "feminine" subjects like cookery and also congregate in the arts disciplines, while boys gravitate towards technical, mathematical and scientific subjects. In fact girls, who desire to study science, are encouraged by their teachers to take biology, excluding physics or chemistry needed for technical and vocational education program.

According to Chege and Sifuna (2006), the nature of stereotyping is such that the stereotypes become accepted through social internalization and because they are accepted, they become difficult or amenable to change. They are lifelong assumptions and so much so deeply ingrained in the mind by early training that render clear thinking concerning them rather impossible.

The dominance of male culture over women is a tradition which socialized women into believing that technical and vocational education is difficult and it is a taboo for her to venture into occupation in the male perspective (Nsofor, 2001). Gender stereotyping is the constant portrayal, such that as in the media or in books, of women and men occupying social roles according to the traditional gender division of labor. There is no doubt this kind of expectation of gender occupational roles could depress their intellectual development, undermine their confidence and dampen their aspirations. In line with the above, Nsofor (2001) observed that from socio-cultural orientation, women generally believe that they are weaker vessels and that rough and tough jobs are meant for boys. This induced wrong perception and negative feelings of women towards technical and vocational education.

\section{Design of the Study}

In qualitative research design can be thought as the logical progression of stages or tasks from problem formulation to the generation of conclusions that are necessary in planning and carrying out a study (Maxwell, 2008). Ritchie and Lwis (2013 p.47) state that is one which has a clearly defined purpose in which there is coherence between the research question and the methods which generate data that is valid and reliable.

It gives direction from the underlying philosophical assumptions to research design and collection. Yin (2003 p.19) adds further that colloquially a research design is an action plan for getting from here to there, where 'here' may be defined as the initial set of questions to be answered and 'there is some set of conclusions. Bogdan (2003) states that it is the entire process of conceptualizing a problem to writing research question and data collection, analysis, interpretation and reporting.

When the understanding of an event is a function of personal interaction and perception of those in that event and the description of the process that characterize the event, qualitative approach is more appropriate than quantitative design to provide the insight necessary to understand the participants' role in the event and their perceptions of the experience. The purpose of this study is to explore without the manipulation of the experience of Nigerian women in maledominated technical and vocational education in the natural setting with the view to interpret phenomena in terms of the meaning individuals attach to them.

The processes of this study's method included investigating, observing and documenting in detail the unique experience of individuals in the male-dominated technical and vocational education. The approach allowed the researcher to collect thick narrative description of the phenomenon under study and gave the researcher the opportunity to take into account the views expressed by the participants and important detail of group interactions and multiple interpretations in the group's natural environment. This qualitative description of their experiences and an inductive analysis of data is most appropriate for the purpose of this research because all these procedures enhanced the possibility for some kind of objectivity which could have been lost if quantitative or experimental strategies were applied (Onwuegbuzie and Collins, 2007).

\subsection{Sampling}

Sampling for this study was driven by the desire of the researcher to learn in detail and in-depth about the experience of individuals. Purposeful sampling is appropriate for use when the author needs to select a sample based on his knowledge of the population, its element and the nature and purpose of the research aim (Creswell, 2012). In this study fourteen women were used. Merriam (2014) suggested that in phenomenological research five to twenty five participants are accepted. Merriam maintains that the small sample size will enable researcher to have an in-depth understanding of the study phenomenon and not seek statistical generalization. The criteria used to select study 
participants are that they have to be women in technical and vocational education, they must have attended primary school for six years, attended a junior secondary school for three years, attended a senior technical college or senior secondary school for three years, have Ordinary National Diploma (OND) certificate in technical and vocational education field from government approved/recognized institution both within and outside the country, have had at least one year work experience before returning to the institution for Higher National Diploma (HND) in technical and vocational education and must be in the first or second year of HND.

\subsection{Data Collection}

Through semi-structured in-depth interviews the researcher attempted to get information about the experience of Nigerian women enrolled in technical and vocational education as to why Nigerian women are misrepresented in this field in Polytechnic institution. The open-ended questions adopted afforded an opportunity for both the researcher and the participants to discuss some topic in more detail. The researcher invited the participants to tell him their experience in this field. As the discussion progressed the researcher adopted counseling skill conversations as well as paraphrasing, probing and reflection to develop the discussion in line with the research objective (Martin, 2013). Subsequently, the researcher conducted fellow-up interviews to either elaborate or confirm emerging themes and categories and their meanings.

\section{Data Analysis}

The qualitative hermeneutic data analysis was used for this study. Data analysis involves examining of people's words and trying to make explicit the knowledge that is in them (Pope et al., 2000). Analysis of the participants' open-ended responses formed the basis for interpreting and finding meaning from the participants experiences. The process of data analysis commenced when the researcher finished his first interview. The analysis of data in qualitative research is a hands-on process that requires the researcher to commit fully to understanding what the data say. The data collected in this study were analyzed inductively and continuously during and after each collection of data. Qualitative researcher constructs a picture which takes shape as he/she collect and examines the parts. The most suitable model for data collection and analysis is one that interweaves them from the beginning (Maguire, 2008). The data analysis for this study involved examining, sorting, categorization, evaluating, comparing, synthesizing and contemplating the coded data as well as reviewing the raw data and recorded data. The author adopted eight steps suggested by Hennie (2009 p.98) as a guide in coding his data.

Even though the model portrays step-by-step procedures, in practice all the procedures work simultaneously" and the author kept doubling back for more collection and coding" (Jones, 2011). The basic strategy the author adopted was to constantly compare the data gathered. The author conducted an interview, made field notes, reviewed document of one incident, and then later compared it to another incident either the same set of data of different set. This led to the formation of tentative categories, which were compared to each other, and also to other instances. The flexible nature of this model resulted in the development of tentative categories and themes. However, the coding and categorizing were finalized only towards the end of the data collection

Data for this study were collected and constantly analyzed as they came in until the eight focus group and seventh oneon-one interviews were conducted and there was no more new information and no new themes or categories had emerged. According to Creswell (2012), this point is called the saturation point where there was no more new information or insights that can be found from the data, the data collection was stopped as saturation has been attained or reached.

\subsection{Strategies the Researcher Employed to Ensure Quality Data}

The researcher in ensuring quality data for this study employed triangulation which encompasses the use of multiple methods Patton (2002) or different source of information (Olsen, 2004). The authors heard the phenomenon in interviews, matched it with what took place in observation and tried to compare it with what the author read in pertinent document and this gave him the confidence that "reality" of the situation as perceived by those in it, was been conveyed as "truthfully" as possible. Furthermore, the author adopted a number of other techniques as recommended by Merriam (2014), which included member checking, peer reviewing and checking to examine the data and comment on the plausibility of the emerging findings, and also providing thick and rich detail of the context of the study. The aim of adopting these methods was to demonstrate credibility, transferability, dependability and conformability. One of the reasons why the author chose to employ member checking was to establish credibility and to verify that his interpretations corresponded with that of the participants

\subsection{Reporting}

In the next section, the researcher describes main themes in detail. The verbatim extract from the data grounds the findings in the data and have allocated numbers to the study participants (N1, N2, N3, N4, to N14) to ensure anonymity. The discussion follows the findings. Consistent with phenomenological approach, the author only integrated relevant literature in the later stage of the data discussion. The discussion of the conceptual framework reflects this.

\section{Findings}

The themes that emerged reflected a wide range of reasons and converged on many issues and concerns about misrepresentation. These reasons are such as Math/Science Phobia, Perceived Social Support, Contextual Roles, Employment Marginalization due to Gender Sensitivity, Career Consciousness, Balancing Family and Work, and Low Career Prestige. All the women acknowledged that misrepresentation of women in technical and vocational education remains an issue in higher education in Nigeria. 
6.1 Math/Science Phobia

Majority of the participants in their reasons for the misrepresentation of Nigerian women in male-dominated technical and vocational education mentioned the fear of math/science as one major factor. The participants expressed that the female students believe that math and science subjects are difficult and prefer to enroll in art courses where these science subjects are not needed. These participants stated that female students believe that science is difficult and fits better for the "guys". The feeling or impression by study participants is that mathematics is difficult and this is built in pupils from primary school an impression they bring to bear in secondary school.

A participant stated that even though mathematics is made compulsory for admission into Higher Institutions of Learning, that most girls do it not for the interest but to enable them meet the requirement for admission. They do not take it serious but only for purpose of gaining admission into program of their choice mostly in art courses. Only very few girls register for further mathematics in the senior secondary school and this is where you find students desiring to go into any science-related program in Institution of Higher Learning of which technical and vocational education is among the science programs. The participants' feeling was that preparing for technical and vocational education and other technical-related programs should begin as early as junior secondary school through senior secondary school.

Participant N7 said the issue of math and science subjects should be properly looked into in the secondary school so that girls can be attracted into this science oriented areas. She also said without these subjects girls cannot major in any technology course. Participant N4 said if Nigeria has to make progress in the field of technology, science courses should not be left in hands of the males alone. Girls should be made to be path of the technological advancement of the country by attracting them to take science subjects in the senior school class. Participant N9 advocated that:

There is need to arose the interest of these girls at very early stage from the primary school. Government should overhaul the syllabus at the primary school with more emphasis on elementary science and mathematics. Girls need to be encouraged from the beginning. Girls should be made to understand from this foundation that science is very important in their life and that the subject is for both boys and girls. If they understand the concept from the beginning they will develop interest in this course as they advance in their educational career.

Participant N11 conveyed that the upbringing of boys and girls creates the dichotomy in TVE field. The culture believe more of the boys and are taught hard way of life. They are prepared for leadership role while the girls are prepared to be mothers. Boys always think that the girls should not go for hard courses. If this impression is erased at the foundation level, more girls will come to terms that they all have the same opportunity in science course. Another participant mentioned that the women found in technology program in Polytechnic institutions are there because of their result in science subjects and recommended that girls should be encouraged to take science course and should also be told that it is not meant for the boys alone. She also stated that the lack of confidence by girls is a factor that prevents them from taking science subjects. They entertain the fear that they do not have the ability to do the science courses. Many girls are afraid of math and science. The general consensus by the study participants is that lack of confidence and fear of math and science is a factor that inhibits girl's enrolment into male-dominated technical and vocational education programs.

\subsection{Perceived Social Support}

Some participants acknowledged that parents play significant role in course selection of their children and were obstacles to women participation in TVE program. Some members of the study participants mentioned that many parents today most particularly some mothers do not encourage their daughters to go into science-related profession, especially a profession in the technical field. According to these participants, parents consider it dangerous and hazardous for women.

Participants were very equivocal in acknowledging the influence of parents especially mothers when it comes to their daughter thinking of a program in technical and vocational education area. As one of the participants mentioned only very few mothers will not advice their daughters against venturing into technical and vocational education and other technical related profession. Some study participants posit that parents are pivotal in girl selection of programs in technical and vocational education fields and as a woman one needs a good parental support to be able to enroll into science and technical programs. As participant N10 stated:

If you don't have a good support from your family, you will not be able to enroll in technical courses and it was as a result of the support I got from my parents that is why I was able to be in the program. Some parents discourage especially women from enrolling into technical and vocational education program because they feel it is difficult and meant for men. They are conscious of their daughters, they want to protect you, so they feel you are going into the boys' area and will prefer you to go into soft areas and that is why those girls who don't have strong desire cannot make it into technical programs.

Parental and family influence on the enrollment of women into male-dominated technical and vocational education and other technical related programs is significant and participants advocate that parents should give their daughters free hand to select program of their choice in institution of higher education. As noted by some participants the lack of interest in technical oriented programs by some parents have resulted in low enrollment of women into male-dominated technical and vocational education and technical related programs in institutions of higher learning in the country. 


\subsection{Contextual Roles}

Participants indicated that the role of the society affected on the women's decision to enroll in technical and vocational education. According to participants, they stated that "traditionally the field of TVE and technical related programs have been dominated by men and not suitable for women and this account for reason why women were encouraged or persuaded to enroll in programs considered to be for women, the liberal arts or social sciences". As some of the participants noted if there are role models in technical and vocational education, women will be inspired to attain such a level. The study participants observed that looking at technical and vocational education environment in Nigeria hardly can they pin point at any successful woman in the field and that if women are there it will promote the interest of girls/young women in this field.

One participant stated that there is this societal belief in Nigeria that women education ends in the kitchen. Another participant stated the society has the perception that women should be teachers and good mothers and house wives. Some of the participants indicated that the Nigerian society continues to place women in inferior position to men and believe that there is no place for women in TVE and other technical related programs in institutions of higher learning. As one participant expressed:

Culture plays a big role in women's career choice in male-dominated technical and vocational education fields. Some culture or religion will not like women dressing or looking like a man. They want to see you in those courses that are associated with women. We thank God for the civilization now if not putting on trouser could hurt some culture or religion. Because to be in technical and vocational education program there are things you do which ordinarily as a woman you will not do and some religion in particular will not accommodate that. Some men will not want to see their wives climbing electric poles or engaged in strenuous practical work. All these are societal factors that count against women and contribute too few women in this field

From the participant's story, it is established that culture and religion have some influence on women's career prospect in TVE and other technical related fields and could account for the few women in the profession.

\subsection{Employment Marginalization due to Gender Sensitivity}

Study participants noted that women in TVE are discriminated against in the labor market. Some participants stated that the discrimination by employers against women with technical and vocational education background is formed by the notion that women will not be able to deliver. This according to study participant's account for reason why some women may not be interested in enrolling into TVE program because, they are not sure of job opportunity on graduation because of their status as women. One participant said that because of lack of career professional women in technical and vocational education field many women do not see it an attractive profession compared to what is found in the liberal art courses where women are well positioned. Participant N10 stated that the discrimination in the labor market discourages women from enrolling in male-dominated technical and vocational education courses as she narrated her story:

My lady friend who graduated HND in electrical engineering went for an interview; she did very well but was told that she was not needed and that they were looking for a male engineer. A lady will be a distraction to male staff in the department. This kind of discrimination weakens me as a woman and could scare women away from enrolling into technical related programs. A situation where you are not valued in the labor market makes one doubt the essence of being in the program. There should be a change as to how women in this field are treated by employers if you are to attract women into this field.

A participant stated: "the labor market believes more in the men than women. They feel that women just pass through the school and that they don't have the experience and technical ability to handle the job required". Another participant said "the labor market take ladies less serious as compared to (male) peer. They feel the profession is for the men, the see women as not belonging to male-dominated technical and vocational education and that is how the society sees it too".

Many of the participants viewed discriminatory market practices as a big factor that inhibits women's desire for maledominated technical and vocational education programs. They feel that they are not recognized because they are women in the field and this according to them has some influence on young girls/women's desiring to come into the program.

\subsection{Role Model}

Majority of the participants expressed lack of mentors in their career aspiration. The participants that spoke on this issue said they had nobody in school to direct them on their career path. The participants noted that in their secondary school period majority of math/science teachers were male and also those that taught introductory technology and technical drawing courses were all males. The feeling of study participant is that seeing women teach in this area that is considered to be for men will give girls the sense of belonging and they will aspire to choose science courses that are pre-requisite for TVE courses. According to them, if there was a mentoring program in the school, it would have helped many girls to learn about what subject was required for technical and vocational education courses. As one participant stated, the "lack of person that we could look on to was a barrier to girls knowing what was expected for technical and vocational education program".

Participant N10 underscored the importance of mentoring with regards to women career prospect: 
It was hard without having female mentors in the field. It would have helped to have someone to talk with about issues. Boys have a lot of people to share with. This is encouraging and motivating because you have somebody to share your academic burden. We ladies don't have the opportunity because of lack of women in this field. Male mentors are helpful with career advice from a male perspective, but it does not feel like they truly understand the burden that we women face, especially in such a male dominated field such as technical and vocational education and other technical programs.

Some participants expressed that despite having nobody to look onto during their secondary school; the guidance counselors where they existed did not help matters as they discouraged girls from pursuing a career in technical profession. As a lady they were always advised to go for social science courses. No counselor ever advised women to go for technical program, even the teachers. Their belief is that technical and vocational courses are meant for men while women should go for the "easier" courses. However, two participants stated that it was as a result of the assistance they got from their experienced teachers that they were able to be in this program.

\subsection{Lack of Career Awareness}

Most of the participants expressed that female students in secondary school were not educated about many of the science-related courses and programs in the field of technical and vocational education in institutions of higher learning. These participants stated that what they read in print Media and watch on the television portrays only boys and men in the field of technical and vocational education programs. According to the participants, the young ones grow up to assimilate that the field of technical and vocational education program is meant for boys. According to the participants, it is among the factors contributing to misrepresentation of women in the field of TVE and other related technical courses. Most of the participants are of the opinion that if there was sound career education or awareness among girl/young women, more girls/young women would have developed interest in this profession. Participant N3 had this to say:

Female students are not provided with useful information about the courses in the field technical and vocational education. The girls need to be properly educated in the secondary school that technical and vocational education courses are not meant for the boys alone. If girls are well informed and encouraged to take science courses more girls will come into this profession

The participants stated that the boys were encouraged to enroll in programs in technical and vocational education and other technical fields while the girls/young women were in most cases persuaded to enroll in arts or social science courses and courses leading to teaching and nursing. To them this has created dichotomy in this field leading to male domination.

\subsection{Balancing family and work}

Balancing family and work as a theme emerged as one of the factors that account for misrepresentation of women in TVE program. Three participants expressed they have problem trying to balance their family with their career. These participants pointed out that they wanted to improve their careers but wished to spend more time with their family. Balancing family and career can sometimes conflict. These participants revealed that they sometime experienced a struggle to maintain a balance between their profession and personal life. The participants discussed having children and the impact their careers had on their family.

One of the study participants who is married stated that because of the strenuous activities involved in technical and vocational education most girls/young women while deciding their career in life will not want to choose the program. She said as a woman where you are made to climb electric poles and work on scaffolds with pregnancy can be scaring to women desiring to come into the program. She went further to say that most husbands will not be glad to see their wife with pregnancy doing hard jobs that could lead to premature delivery. According to her, it is among reasons that good number of technical firms does not employ women engineers because they feel one will not be able to perform like the men. Girls will prefer corporate or office work where they can manage their office and family. Participant N4 who worked on the site from her home had this to say:

I was involved in supervising some projects. There was some occasion I slept outside my home because there was pressure on us to see that the project was completed on schedule. I spend a lot of time from home and my children see me as a non-caring mother. It is not easy when it involves traveling out of your station as woman to supervise a project that involves sleeping outside your home. You need to have a good husband and these are issues with women in this field. It counts when young women consider a profession.

Some participants even though not married but based on their experience during the industrial work experience expressed the feeling of ability to cope with TVE demand and family responsibilities. They said with what is involved in technical and vocational education if they will be able to cope with pregnancy and also having to take care of the family and other domestic activities.

\subsection{Low Career Prestige}

Many of the participants attributed among reasons for the misrepresentation of women in technical and vocational education to the fact that many young girls/women see the profession as dirty and dangerous. The way people in technical and vocational education look appears dirty to young girls/women. Women prefer to look 'corporate' rather than dressing in the manner they find people in technical and vocational education profession. They see people in technical and vocational education to be exposed to hazardous environment, work on greasy machine and involve in 
dirty work. According to the participants, the public sees technical and vocational education profession as that of a laborer because of the way they dress or look. This according to study's participants can be intimidating and it sends fear into the young girls/women about the nature of the profession. As one participant stated:

Some young women who are full of entertainment and "fashion freak" they feel technical and vocational education generally is a dirty discipline. They feel they can't tend to dress the way technical and vocational professionals do. They can't afford being in the discipline. They can't change their dressing pattern, so it affects them in that aspect when it comes to considering a program in technical related profession. Some girls also consider themselves to be pretty to go into technical program.

The thinking of the participants is that girls' consider technical and vocation education, professional work in the bush, climbing poles and doing other similar things unwomanly and this to them scares women from considering taking up a profession in the technical fields. Stressing further, participant N7 said unless you have really made up your mind to go into technical related program if not the way those in this profession appear and the job they are exposed to can be discouraging to young girls who are not properly counseled on technical and vocational education profession.

Participant's expressions portray that many young girls/women are scared from considering a profession in the technical field because of the way they see those in the profession, the way they appear, the work they are exposed to. They views of the participants is that the only way this impression can be erased from these girls/young women's memory is through proper counseling and awareness because the dressing and the job involved are all part of the profession.

\section{Discussion}

Among reasons advanced by participants for misrepresentation of women in male-dominated technical and vocational education is fear of math/science subjects. This originates from secondary schools where the foundation for technical and vocational education is laid as many girls shy away from science subjects believing that they are not capable of doing it.

The findings according to much of the literature in this field would lay in the various socio-cultural barriers in technical and vocational education that women experience. FAWE (2005) observed and stated that the gender stereotypes in educational system only portray that there are masculine subjects such as mathematics, science, technology while the feminine subjects are home economics, secretarial studies and literature. Majority of women saw math/science as men's profession (Ndahi, 2002).

Many women have lost interest in math/science believing that they will not do well. Study by Goodman et al., (2002) shows that women have reported lower levels of self confidence than men in their math and science abilities- a factor that researchers have identified as important for success in STEM field. A lack of confidence in math/science ability deprive many women from participating in STEM fields (Goodman et al., 2002)

The argument that parent and family support are among the factors preventing women from considering a career in technical and vocational education and other science oriented career is declared and proved in the majority of the related literature (FAWE, 2005; Ndahi, 2002; Otto, 2000). In this study participants indicated that parents and family had an impact on the career aspiration of women into technical and vocational education program which may be associated with the misconception of the Nigerian society as noted by participants that technical and vocational education is difficult and better fits for the men. This is in line with Adya and Kaiser's (2005) study on early determinant of women in IT workforce: a model of girls' choice which found that the impact of parental guidance is felt unequivocally in the choice of traditional and nontraditional careers, and that it is most strongly observed in the choice of technical and vocational education

The findings of this study showed young Nigerian women's disposition toward-and hence achievement in TVE and science related programs which are believed to be socialized as well as inculcated by society that tends to view technical and vocational education as male inclined. Societal beliefs in Nigeria continue to play a key role in perpetuating gender practices and identity stereotypes within the TVE discipline that are hindrance to women's participation in this field and other technical-related programs. Study by Egun and Tibi (2010) on the gender gap in technical and vocational education in the Midwestern Nigeria asserts that the cultural practices, attitudes, customs, behavioral decisions and procedures are obstacle to women participation in STEM.

Societal belief in Nigeria about gender has channeled men and women in substantially different career direction (Goodman et al., 2002). Sex stereotyped occupation of the male over female does a culture that has reinforced the notion of Nigerian women's belief that TVE is a preserve of the males. Because of this societal perception young people employ these stereotypes as a tool in their quest for work and career aspiration. Society through gender and stereotypes, socialize young men and women differently. This suggests that they may develop different hierarchies of core personal values. Nigerian culture has not considered girl and young women education as important particularly in TVE field and other technical related programs. Due to the lack of emphasis, this has resulted in misrepresentation of women in this field.

A major concern of participants of this study is the discriminatory market practices against women in TVE field. As stated by some of the participants, the discrimination in the labor market discourages women from enrolling in TVE courses. One of the participants narrated her story: "My lady friend who graduated Higher National Diploma (HND) in Electrical Engineering went for an interview; she did very well but was told that she was needed and that they were looking for a male engineer. A lady will be a distraction to male staff in the department. I think she was not taken because she is a woman even when they know that she is qualified. This kind of discrimination weakens me as a woman 
and could scare women away from enrolling into technical related programs". This is line with Hegewisch et al., (2010) study which found, that women are discriminated against in hiring (and promotion) when they appear with all the same skills and abilities as their male counterparts. This discriminatory labor market practice send some wrong signals to young women who may desire to come into technical and vocational education field that they do not have a place in the labor market. Literature suggests that it is necessary to address the urgent needs of these women who are less able to assert themselves in the labor market.

Findings reveal that not many of the participants had opportunity for mentor and role models however; they believed that mentoring was needed for Nigerian women. In interview with participants, the yearning for female mentors and role models was palpable. Young women in technical and vocational education students want to look up and see in the field with whom they can share their issues and dealing with the security that comes with being a woman in technical and vocational education. Research findings show that the implementation of mentoring program was significant for women in technical and vocational education and science-related fields ( Bagilhole et al., 2002)

Many of the participants for this study had no formal mentoring but found their support externally from friends and internally from their parents. Young women in technical and vocational education studies expressed strong desire for mentors-who could offer advice and guidance. As participant noted "If there was a mentoring program in the school it would have helped many girls to learn about what subject was required for technical courses. " Another participant also stated the lack of person that they could look on to was a barrier to girls knowing what was expected for technical and vocational education programs". But meeting this need is a difficult task because of the shortage of the Nigerian women in this position.

Researchers have found that mentors and role models affect career aspiration and career indecision towards nontraditional career choice (Quimby and Santis, 2006). Smith and Dengiz (2010) outlined women studies indicating that women have fewer opportunities than male peers and acutely feel that this is as a result of lack of role models. Some other researcher have also shown that the situation that prevent women from finding or even seeking employment in TVE fields is as a result of few women role models who could inform women students about opportunities in these fields (Samulewicz et al., 2012). A study by Kodate et al., (2014) underscores the need for invigorating mentors' role in order to secure a more equitable future for women in technical and vocational education.

Institutions and government of Nigeria have to consider implementing not only formal mentoring program but also providing forums for informal mentoring programs. Mentoring is very important for professional growth or career aspiration for both men and women. A network of supportive women (within and outside the school) would not only help Nigerian women aspiring into technical and vocational education but could also assist them build knowledge that is vital for advancement in this field.

Among reasons advanced by participants for misrepresentation of women in technical and vocational education is lack of career information in the field. Participants expressed that what they read in the print media and watched on the television portrays only boys and men in the field of technical and vocational education. According to the participants, young ones grow up to assimilate that the field of technical and vocational education is meant for the boys.

Literature found that generally there is a lack of information about technical and vocational education opportunities and choices for women. The lack of information about TVE has led to the popular misconception as held by women that this field is a male domain. For many women this is not an attractive career option because of lack of career consciousness in this field. Cohen et al., (2012), advocates that teachers and counselors can begin to infuse career information, rather than to detract from science content. Awareness of STEM careers is important for all students because the knowledge of science is important for understanding the role of technology in our society (Cohen et al., 2012). Similarly, Samulewicz et al., (2012) have recommended that there is a need to create science awareness among women so as to attract them into science-related fields.

Some participants expressed the difficulty of balancing work and family responsibilities. The fact that women still comprise the part of the population that must adjust their lives to accommodate a family creates substantive inequality in Nigerian society. Furthermore, the challenge of balancing work and family produces barriers for women in technical and vocational education environment. Some literature suggests that work family conflict critically challenges for women in TVE causing an impact on women's attitude and work behavior (Bartol and Aspray, 2006). A survey of women scientists and engineers who received POWRE award from the National Science Foundation found that $70 \%$ of women from both group listed balancing work and family responsibilities as the most difficult issue they faced (Rosser and Zieseniss, 2000). The demand of work as revealed by study participants coupled with the demand of family can become problematic for some women in TVE as they seek creative ways of continue maintaining their family responsibility and contend with the increasing demand and pressure arising from their TVE environment.

Similarly, concern about how to balance work and family appears to be a recurring issue in the research factors that keep girls and young women from pursuing scientific and technical and vocational education careers. A study of high school students found that women are less likely to choose high prestige occupation in the science and engineering because of doubt about balancing work and family responsibilities (Legewie \& DiPrete, 2012). These girls and young women often are told that successful careers in science and science related fields requires complete commitment to their professional lives that then leaves little time for personal lives. The findings of the study of high school graduates found that young women's anticipation of conflicts between family and career responsibilities rather than their actual experience negatively affected their perception of science and science-related careers. In order to address the issue of balancing work and family which has become an impediment to women participation in science and engineering programs, Hill et al., (2010) emphasizes the need for family-friendly policies and called for organizations "to 
encourage among employers a healthy balance between their work and personal lives through flexible functional work policies and attitudes".

It appears women seemed to have accepted negative perception about TVE and technical- related programs. The metaphor of TVE as being dirty profession was mentioned by majority of the study participants during the course of the interview with a frequency that places it at the centre of generally held conception of the profession. This echoes the findings by Driggers (2013) on optical engineering to 14-year-old girls and her interview to find out the reasons behind gender disparity in engineering. These girls said that most girls who go into professional careers are interested in medicine or law because these careers are interesting, glamorous and gratifying. It implies that girls are conscious of their appearance or look in considering a career. It is no doubt as noted by some participants that the public image of technical and vocational education to certain extent is synonymous with that of a laborer and this seen as inconceivable in terms of femininity. These beliefs have been shown by other scholars to be significant in the earliest stages. By the time they come to school, children already have ideas which you need to break down (Phipps, 2002).

\section{Conclusion}

In this study, the author specifically wanted his audience to hear the voice of Nigerian women's as to why women are misrepresented in male-dominated technical and vocational education program. Result of this study reveals that women in male-dominated technical and vocational education encountered challenges: however, they opted not to let these obstacles overcome them. It is hoped that implementation of this study could lead to better women population balance and reverse the trend of misrepresentation of women in male-dominated technical and vocational education. An increase in women population in TVE and related courses could lead to a great exposure of postsecondary opportunities in the area of science, technology, engineering and mathematics.

Most importantly, given the present economic and employment needs of the Nigerian citizenry, the stakeholders in education should strengthen the existing programs and encourage women to explore the study of science at secondary school and TVE at postsecondary education. The experience of these women should offer insight to other Nigerian girls/young women aspiring to enroll in male-dominated technical and vocational and also contribute to the body of literature from which other women can draw.

\section{Limitation of the study}

The present research is an exploratory study of misrepresentation of women in male-dominated technical and vocational education in one Polytechnic. The study did not make comparisons between female students from different institutions. In addition, due to the nature of the study with limited number of subjects, the findings may not be generalizable to other samples and population. This is because the focus of the study was to provide an in-depth understanding of the misrepresentation of Nigerian women in male-dominated technical and vocational education at a polytechnic institution. The findings however, may be useful to any population which has similar characteristics to the sample of the present study (Merriam, 2014)

\section{Recommendations}

Previous research and findings of this study agreed that parents played a significant role in the career choice of their children (Egun \& Tibi, 2010). Therefore, in order to possibly add to the population of women in technical and vocational education, they following recommendations are made. Parents should provide a gender-neutral environment free from stereotypical bias and concern. This freedom will allow young girls and women to discover their hidden talents and skills. Parents need to support and advocate for their children. As their daughters choose the less traveled root or road, viewing them as pioneers and not traitor to the gender is recommended.

Parents need to help their daughters during their entire academic career by finding and creating opportunities for them that may not have been previously available. This includes encouraging their daughters to enroll in the more rigorous mathematics and science courses, talking to administrator and those involved with educational planning to create courses and clubs that would be advantageous for young girls and women who are interested in technical and vocational education and technical-related fields.

They believe that young girls and women need to be good in mathematics and science, taking classes that challenge them. This is also the time when young girls and women need to become proud of their academic skills, even though they may face some opposition or be shunned by their males or boys who may reject them because of their achievements.

The participants also believe that young girls and women need to create a support system that encourages them and does not belittle their accomplishments. All women can research technical and vocational education and join related academic clubs. They must be proactive in their educational pursuit. Girls can join their TVE clubs and talk to both female and male TVE students to find out what they do. As time gets closer, visiting college campus and talking to those in the major will further their understanding.

There is a need to encourage the creation of a critical mass of women faculty members in TVE and technical-related departments by administrators of TVE programs. This study has identified the absence of women in visible positions in TVE as among the reasons women are not developing interest in this field because it is declaration that they are not wanted in the profession. It is imperative, therefore, for administrators to note that there is a need to recruit professional women into this field so as to boast the moral and interest of young girls and women desiring to come into the program.

Research has shown the important role teachers and counselors play in the career choice of students. Participants of this study stated that among the reasons girls are shying away from TVE is the impression of some teachers and counselors 
that make them to believe that TVE and other science-related courses are better fit for men as they are advised to go into social science or liberal arts courses believing that they are better fit for women. Findings from participants indicated that poor TVE knowledge by teachers and counselors has resulted in some teachers and counselors' not advising young girls and women on the career prospects that exist in this field.

In order to get a more comprehensive picture of the misrepresentation of Nigerian women in male-dominated technical and vocational education, future studies should include women who have graduated from this program and currently working in male-dominated technical and vocational environment. Having observed the effect of cultural traditions, religion and gender stereotypes from study participants' narratives, the author suggest that future study should also investigate how different culture and religion affects the access and participation of women in male-dominated technical and vocational education.

\section{References}

Adya, M., \& Kaiser, K. M. (2005). Early determinants of women in the IT workforce: a model of girls' career choices. Information Technology \& People, 18(3), 230-259.

Aguele, L. I., \& Agwagah, U. N. V. (2007). Female Participation in Science, Technology and Mathematics (STM) Education in Nigeria and National Development. J. Soc. Sci, 15(2), 121-126.

Ajewole, G. A. (2000). Teaching science for gender equity under the Universal Basic Education (UBE) programmme. (Paper presented at the national conference, oganized by Nigerian Academy of Education of University of Benin. 6-10 Nov).

Akpotor, J. (2015). Empowerment: A Millenum Development Goal, Journal of Gender and Behaviour,7(2),25042517.

Alabi, T., Bahah, M., \& Alabi, S. O. (2014, January 31). The Girl-Child: A Sociological View on the Problems of GirlChild Education in Nigeria. European Scientific Journal. 10(2), 1857-7881

Alamina, J. I. (2001). An impediment to women in science; cultural influence and the way forward STAN P.62.

Bagilhole, B. (2002). Women in non-traditional occupations [Electronic book]: challenging men. Palgrave Macmillan.

Bartol, K., \& Aspray, W. (2006). The Transition of Women form the Academic World to the IT Workplace: A Review of the Relevant Research.

Bogdan S., R. \& B. (2003). Qualitative research methods for education: an introduction to theories and methods (4th ed.). Boston: Allyn \& Bacon.

Cohen, C., Patterson, D. G., Kovarik, D. N., \& Chowning, J. T. (2012). Fostering STEM Career Awareness : Emerging Opportunities for Teachers, Journal of Research, Leadership and Practice, 6(2), 12-17.

Creswell, J. W. (2012). Qualitative Inquiry and Research Design: Choosing Among Five Approaches (p. 472). SAGE Publications.

Driggers, R. (2013). Optical Engineering to a 14-Year-Old Girl. Optical Engineering, 52(8).

Duman, S. \& Margolin, G. (2007). Parents' Aggressive Influences and Children's Aggressive Problem Solutions with Peers. Journal Clin Child Adolesc Psychol, 36(1), 42-55.

Egun, A. C., \& Tibi, E. U. (2010). The gender gap in vocational education: Increasing girls' access in the 21 st century in the Midwestern States of Nigeria. International Journal of Vocational and Technical Education, 2(2), 18-21.

FAWE. (2005). Creating an enabling and empowering environment for women in teriary eucation. A handbook for African Universities, Nairobi.

FME, (2004). Federal Ministry of Education. National Policy on Education. Lagos.

Franks, K. I. M., Schurink, W., \& Fourie, L. (2006). Exploring the Social Construction of Life Roles of Career-Oriented Women, 32(1), 17-24.

Goodman R. (2002). Final Report of the Women's Experiences in College Engineering (WECE) Project. Cambridge, MA: Author.

Hegewisch, A., Liepmann, H., Hayes, J., \& Hartmann, H. (2010). Separate and not equal? Gender segregation in the labor market and the gender wage gap. IWPR Briefing Paper, 377.

Hennie, R. B. (2009). Analysis in Qualitative Research. Sage Publication, Thosand Oaks.

Hill, C., Corbett, C., \& St Rose, A. (2010). Why So Few? Women in Science, Technology, Engineering, and Mathematics. ERIC.

Jones, M. (2011). Guiding the use of Grounded Theory in Doctoral studies - an example from the Australian film industry, 6, 95-114.

Kodate, N., Kodate, K., \& Kodate, T. (2014). Paving the way and passing the torch: mentors' motivation and experience of supporting women in optical engineering. European Journal of Engineering Education, (ahead-of-print), $1-18$. 
Legewie, J., \& DiPrete, T. A. (2012). High School Environments, STEM Orientations, and the Gender Gap in Science and Engineering Degrees. STEM Orientations, and the Gender Gap in Science and Engineering Degrees (February 21, 2012).

Lohan, M., \& Faulkner, W. (2004). Masculinities and technologies. Men and Masculinities, 6(4), 319-329.

Maguire, L. L. (2008). Developing Distance Education Policy Within A State System of Higher Education: The Faculy Perspective. Retrieved from file:///C:/Users/dll/Downloads/Dissertation_FINAL.pdf

Martin, P. G. (2013). The experiences of women in male-dominated professions and environments in South Africa.

Maxwell, J. A. (2008). Designing a Qualitative Study, 214-253.

Merriam, S. B. (2009). Qualitative research: A guide to design and implementation. John Wiley \& Sons.

Merriam, S. B. (2014). Qualitative Research : Aguide to Design and Implementation. John Wilsey and Sons.

Ndahi, H. (2002). Gender inequity in industrial and technical education in Nigeria: parents' perspectives in the 21st century. Journal of Industrial and Technical Education in Nigeria, 39(2), 17-29

Ndahi, H. B. (2002). Gender inequality in industrial and technical education in Nigeria: Parents perspective in the 21st century. Journal of Indutial and Technical Education in Nigeria, 39(2), 17-29.

Nsofor, C. C. (2001). Cultural impediments on women in Science, Technology, and Mathematics Educatuion in Nigeria. Stan, 37(1-2), 48-51.

Ogbuanya, T. C. (2008). Women and national development. Lead paper presented at National Association of Technical Teachers (NATT) held at College of Education, Umunze, February 19th-22nd.

Okpoko, A. (2005). Strategies for overcoming the barrier to girls' education in Nigeria. Journal of Forum for African Women Educationalists Nigeria, 1(3), 105-111.

Okpoko, J. A. (2005). Strategies for overcoming the barriers to girls' education in Nigeria. International Journal of Forum for African Women Educationalists Nigeria, 1(3), 105-111.

Olsen, W. (2004). Triangulation in social research: qualitative and quantitative methods can really be mixed. Developments in Sociology, 20, 103-118.

Omadjohwoefe, O. S. (2011). Gender Role Differentiation and Social Mobility of Women in Nigeria, Journal of Social Science, 27(1), 67-74.

Onwuegbuzie, A. J., \& Collins, K. M. T. (2007). A typology of mixed methods sampling designs in social science research. The Qualitative Report, 12(2), 281-316.

Otto, L. B. (2000). Youth perspective on perntal career influence. Journal of Career Development, 27(2), 111-118.

Patton, M. Q. (2002). Qualitative research and evaluation methods (3rd ed.). Thousand Oaks. CA: Sage.

Phipps, A. (2002). Engineering Women: The 'Gendering' of Professional Identities, International Journal of Engineering Education, 18(4), 409-414.

Pope, C., Ziebland, S., \& Mays, N. (2000). Qualitative research in health care. Analysing qualitative data. BMJ (Clinical Research Ed.), 320(7227), 114-6.

Quimby, J. L., \& Santis, A. M. (2006). The influence of role models on women's career choices. The Career Development Quarterly, 54(4), 297-306.

Raghuram, P. (2008). Migrant Women in Male-dominatedsectorsof the labor market a research agenda. Population, Space and Place, 14(1), 43-57.

Ritchie, J. \& Lwis, j. (2013). Qualitative Research Practice: A Guide for Social Science Students and Researchs. Sage Publication. Thousand Oaks.

Rosser, S. V, \& Zieseniss, M. (2000). Career issues and laboratory climates: different challenges and opportunities for women engineers and scientists (survey of fiscal year 1997 POWRE awardees). Journal of Women and Minorities in Science and Engineering, 6(2), 1-23

Samulewicz, D., Vidican, G., \& Aswad, N. G. (2012). Barriers to Pursuing Careers in Science, Technology, and Engineering for Women in the United Arab Emirates. Gender, Technology and Development, 16(2), 125-152.

Simmons, A. N. (2008). A Reliable Sounding Board: Parent Involvement in Students' Academic and Career Decision Making. NACADA Journal, 28(2), 33-43.

Smith, A. E., \& Dengiz, B. (2010). Women in engineering in Turkey-a large scale quantitative and qualitative examination. European Journal of Engineering Education, 35(1), 45-57.

Yin, R. K. (2013). Case Study Research: Design and Methods (p. 312). SAGE Publications. 